\title{
Pengembangan Kreativitas Pengolahan Sampah Plastik melalui Pemberdayaan Wanita di Kalisegoro Semarang
}

\section{Creativity Development of Plastic Waste Processing by Women Empowerment in Kalisegoro Semarang}

\author{
Dyah Ayu Widyastuti ${ }^{i^{*}}$, Rivanna Citraning Rachmawati ${ }^{2}$, Atip Nurwahyunani ${ }^{3}$ \\ ${ }^{1,2,3}$ Pendidikan Biologi, Universitas PGRI Semarang, Semarang, Indonesia \\ *dyah.ayu@upgris.ac.id
}

Riwayat Artikel: Dikirim 7 Januari 2020; Diterima 15 Mei 2020; Diterbitkan 20 Mei 2020

\begin{abstract}
Abstrak
Sampah rumah tangga yang belum diolah menjadi salah satu masalah yang dihadapi oleh masyarakat Kelurahan Kalisegoro Kecamatan Gunungpati Kota Semarang. Masyarakat hanya menggantungkan pengelolaan sampah pada jasa angkut sampah untuk selanjutnya dibuang di tempat pembuangan akhir. Kebiasaan tersebut menjadikan sampah rumah tangga di Kalisegoro tidak terolah dengan baik dan dikhawatirkan semakin mencemari lingkungan. Pelatihan pengolahan sampah rumah tangga sangat diperlukan untuk meningkatkan kemampuan masyarakat Kalisegoro, terutama ibu rumah tangga agar sampah dapat tertangani dengan baik. Kegiatan ini bertujuan untuk meningkatkan kreativitas dalam mengolah sampah plastik melalui pemberdayaan wanita di Kelurahan Kalisegoro Kecamatan Gunungpati Kota Semarang. Sampah plastik yang dapat diolah dengan baik menjadi kerajinan tangan mampu mengurangi penumpukan sampah yang dapat mencemari lingkungan. Kegiatan diikuti oleh ibu-ibu yang tergabung dalam Unit Usaha Dorang Dawis Anggrek 17 di Kelurahan Kalisegoro Kecamatan Gungpati Kota Semarang.
\end{abstract}

Kata kunci: sampah plastik, pengolahan sampah, pemberdayaan

\begin{abstract}
Unprocessing household waste is one of environmental problem which has to be overcome by Kalisegoro society. People only depend on garbage transport service to process household waste henceforward to final disposal site. Those habit leads to unprocessing household waste in Kalisegoro and more contaminate the environment. Household waste processing training is required to enhance the ability of Kalisegoro society, especially for housewife so that the household waste can be handled well. This program intend to enhance creativity of housewife in Kalisegoro to process plastic from household waste. Plastic waste can be processed become handycrafts and reduce rubbish buildup which leads to environmental pollution. The participant of this program is household who incorporated in Dorang Dawis Anggrek 17 business unit in Kalisegoro Gunungpati Semarang.
\end{abstract}

Keywords: plastic waste, waste processing, empowering

\section{PENDAHULUAN}

Jumlah penduduk yang semakin besar diikuti pula oleh beberapa masalah yan butuh penanganan segera. Permasalahan seperti wilayah pemukiman, lapangan pekerjaan, kesenjangan sosial, hingga permasalahan sampah merupakan masalahmasalah ikutan dari pertambahan jumlah penduduk (Nugraha dkk., 2007; Nurjazuli dkk., 2016; Sahil dkk., 2016). Masalah yang paling banyak disoroti saat ini adalah masalah pengolahan sampah yang belum optimal. Peningkatan masalah sampah yang tidak terolah seringkali terkait dengan tidak tersedianya sarana dan prasarana untuk pengolahan sampah (Subekti, 2010).

Sarana dan prasarana pengolahan sampah yang terbatas menjadikan masyarakat kesulitan untuk mengolah sampah terutama yang berasal dari rumah tangga. Sampah rumah tangga seringkali sulit diolah karena masih bercampur antara 
sampah organik dan anorganik sehingga pemulung pun enggan mengambil sampah tersebut. Padahal, Peraturan Pemerintah Nomor 81 Tahun 2012 tentang Pengelolaan Sampah Rumah Tangga dan Sampah Sejenis Sampah Rumah Tangga telah mengatur pemilahan sampah yang baik berdasarkan jenisnya (Yudistirani dkk., 2015).

Sampah rumah tangga sebaiknya dipilah menjadi kelompok sampah organik dan anorganik sehingga masing-masing sampah tersebut dapat diolah menjadi bentuk lain yang lebih bermanfaat. Masyarakat Kelurahan Kalisegoro Kecamatan Gunungpati Kota Semarang perlu memperoleh pengetahuan dan wawasan baru mengenai pengolahan sampah rumah tangga, terutama sampah plastik. Keterampilan dan kreativitas masyarakat tersebut dalam mengolah sampah plastik diharapkan dapat meningkatkan pendapatan rumah tangga melalui penjualan produk hasil olahan sampah platik.

Sampah rumah tangga di Kelurahan Kalisegoro Kecamatan Gunungpati Kota Semarang yang biasanya hanya dibuang ke tempat pembuangan akhir dapat dimanfaatkan menjadi produk-produk bernilai ekonomi tinggi. Hal tersebut dapat tercapai melalui adanya pelatihan bagi masyarakat khususnya wanita ibu rumah tangga di Kelurahan Kalisegoro untuk dapat memilah sampah rumah tangga dan kemudian mengubahnya menjadi produk olahan sampah yang dapat dijual. Pengolahan sampah plastik tersebut selain dapat meningkatkan pendapatan masyarakat, juga dapat membantu mengatasi masalah tumpukan sampah yang mencemari lingkungan(Wahyono, 2001). Sampah plastik yang sulit terdegradasi dapat dimanfaatkan sehingga tidak lagi menjadi sumber pencemaran lingkungan (Kurniaty \& Rizal, 2011).

\section{METODE}

Pelaksanaan program dibagi menjadi beberapa kegiatan, meliputi penyuluhan dan focus group discussion (FGD), pelatihan dan praktik mandiri, serta monitoring dan evaluasi. Tahapan pelaksanaan kegitan tersebut adalah sebagai berikut:

\section{a. Penyuluhan dan FGD}

Kegiatan penyuluhan dan FGD dimaksudkan untuk membuka wawasan mengenai pemilahan sampah organik dan anorganik. Masyarakat diminta untuk mendiskusikan permasalahan terkait sampah rumah tangga serta mencari solusi dari permasalahan tersebut. Pada kegiatan ini, masyarakat diberikan gambaran pengolahan sampah rumah tangga secara umum, terutama pengolahan sampah plastik.

\section{b. Pelatihan dan praktik mandiri}

Pelatihan dilakukan dengan memberikan demonstrasi pengolahan sampah plastik menjadi kerajinan tangan terlebih dahulu sebelum masyarakat diminta untuk praktik mandiri. Demonstrasi dimaksudkan agar peserta pelatihan memperoleh gambaran umum untuk mengolah sampah plastik menjadi berbagai bentuk kerajinan yang bernilai ekonomis tinggi. Pada tahapan selanjutnya, peserta pelatihan diberikan kesempatan untuk mengolah sampah plastik menjadi kerajinan berupa bros dan tas. Pengolahan dilakukan secara sederhana agar dapat memanfaatkan peralatan yang dimiliki peserta di rumah.

\section{c. Monitoring dan evaluasi}

Kegiatan ini dilakukan untuk melihat kemampuan yang dimiliki oleh peserta setelah pelatihan dan praktik mandiri pengolahan limbah plastik menjadi bros dan tas. Evaluasi juga dilakukan untuk melihat seberapa besar peningkatan keterampilan dan kreativitas peserta dalam meningkatkan 
nilai ekonomi sampah plastik menjadi kerajinan dengan nilai ekonomi yang lebih tinggi.

\section{HASIL DAN PEMBAHASAN}

Program ini dilaksanakan di salah satu rumah warga yang terletak di RT 06 RW 03 Kelurahan Kalisegoro Kecamatan Gunungpati Kota Semarang. Kegiatan yang pertama dilakukan adalah penyuluhan dan focus group discussion (FGD) mengenai pemilahan sampah organik dan anorganik. Masyarakat diberikan penyuluhan mengenai pemilahan sampah rumah tangga sehingga diharapkan sampah organik dan anorganik tidak lagi tercampur dan menjadi lebih mudah untuk diolah menjadi produk lain. Prinsip 3R (reuse, reduce, recycle) dapat diterapkan dalam pengolahan sampah sehingga dapat mengurangi jumlah timbunan sampah (7). Masyarakat juga diberikan pengetahuan mengenai bahaya sampah bagi lingkungan dan upaya yang dapat dilakukan untuk mengatasi bahaya sampah tersebut.

Focus group discussion (FGD) dilakukan untuk mempertegas pengetahuan masyarakat mengenai permasalahan yang dapat timbul akibat penumpukan sampah dan bagaimana cara mengatasinya. Kegiatan ini difokuskan pada kemampuan masyarakat untuk menemukan solusi dari permasalahan sampah yang selama ini mereka hadapi. Solusi yang muncul dari pikiran masyarakat sendiri diharapkan dapat diterapkan dalam kehidupan mereka sehari-hari.

Gambar 1:

Penyuluhan mengenai pemilahan sampah organik dan anorganik

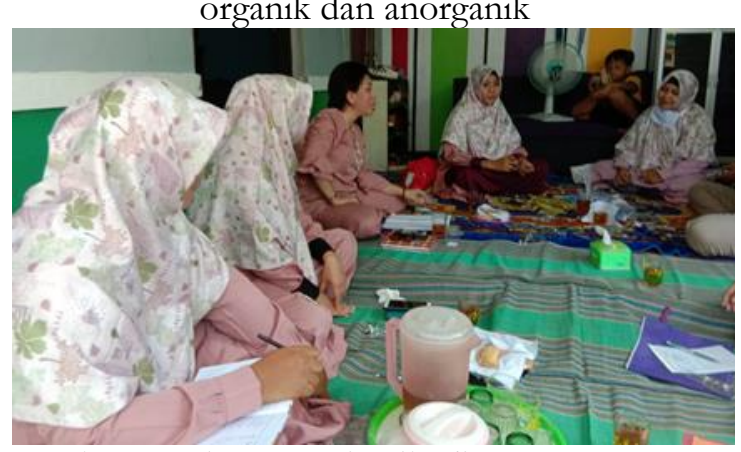

Sumber : Dokumentasi Pribadi
Kegiatan selanjutnya adalah pelatihan pembuatan kerajinan tangan dari sampah plastik, berupa bros dan tas. Sampah plastik yang digunakan untuk pembuatan kerajinan tangan harus dicuci bersih terlebih dahulu kemudian dikeringkan agar siap digunakan. Sampah plastik bekas bungkus kopi dapat dijadikan sebagai bahan pembuatan bros. Sedangkan untuk pembuatan tas dapat menggunakan sampah plastik bekas detergen dan lainnya.

Peserta pelatihan yang marupakan ibu-ibu rumah tangga yang tergabung dalam PKK Kelurahan Kalisegoro Kecamatan Gunungpati Kota Semarang nampak antusias dalam mengikuti pelatihan pembuatan bros dan tas dari sampah plastik. Bros dibuat dengan pola kelopak bunga dengan cara membentuk kelopak dari bungkus kopi kemasan kemudian masing-masing kelopak yang sudah dibentuk digabungkan satu dengan yang lain menggunakan benang dan jarum.

Gambar 2:

Pelatihan pembuatan bros dari sampah plastik kemasan kopi

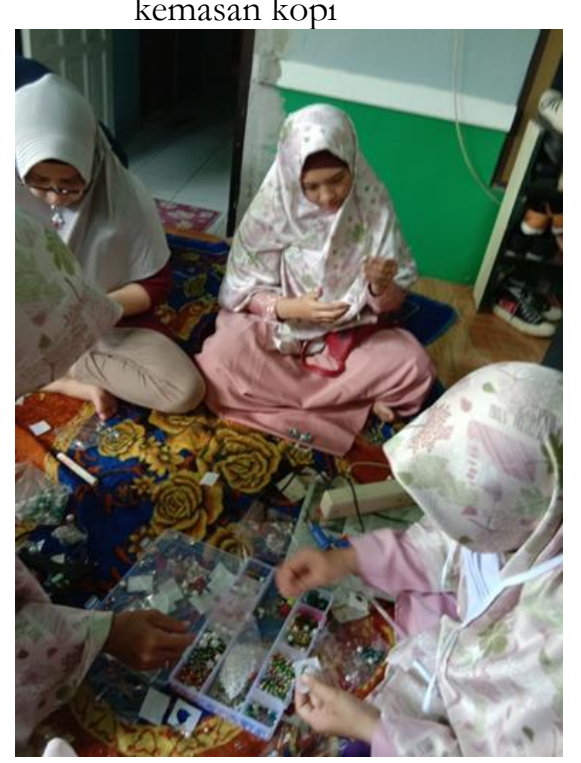

Sumber: Dokumentasi Pribadi

Pelatihan kedua adalah pembuatan tas dari sampah plastik kemasan deterjen maupun yang lainnya. Peserta diberikan pelatihan cara melipat sampah plastik hingga membentuk pola tertentu yang 
nantinya akan disatukan untuk membentuk tas. Peserta pelatihan sangat antusias mengikuti tahapan pembuatan tas, mulai dari pemotongan bahan, pelipatan, pembentukan pola, penggabungan, hingga penambahan aksesoris pada tas sampah plastik.

Gambar 3:

Pelatihan pembuatan tas dari sampah plastik

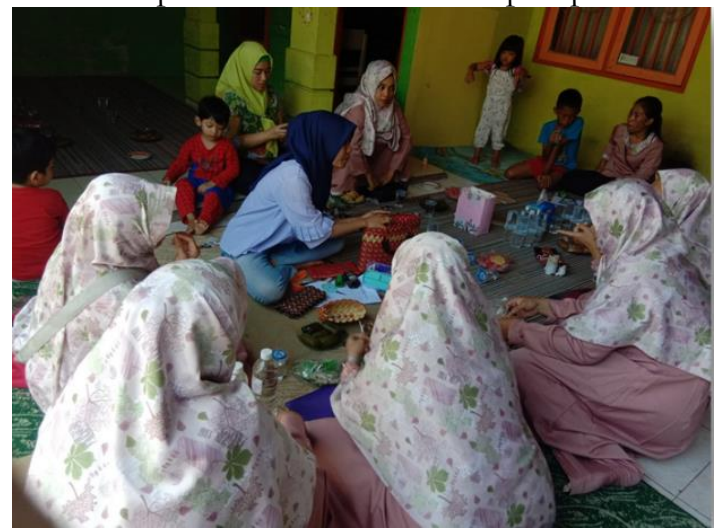

Sumber: Dokumen Pribadi

Peserta pelatihan kemudian diberikan kesempatan untuk praktik mandiri membuat kerajinan dari sampah plastik berupa bros dan tas sesuai dengan kreativitas masing-masing. Bros dan tas dari sampah plastik tersebut dapat dijadikan sebagai sumber pendapatan tambahan bagi ibu-ibu peserta pelatihan sehingga dapat meningkatkan pendapatan rumah tangga.

Peserta pelatihan terlihat memberikan respon yang sangat baik. Mereka sangat antusias dalam mengikuti arahan pembuatan kerajinan sampah baik berupa bros maupun tas. Peserta juga antusias dalam mengajukan pertanyaan apabila ada tahapan yang belum dimengerti. Meskipun pekerjaan tangannya belum begitu rapi di praktik mandiri yang pertama, namun dengan terus berlatih, kemampuan peserta pun semakin meningkat. Hal tersebut terlihat saat monitoring dan evaluasi kegiatan. Kerajinan tangan berupa bros dan tas yang dibuat oleh peserta pelatihan terlihat lebih rapi daripada percobaan sebelumnya.
Gambar 4:

Bros dari sampah plastik hasil kreativitas peserta pelatihan

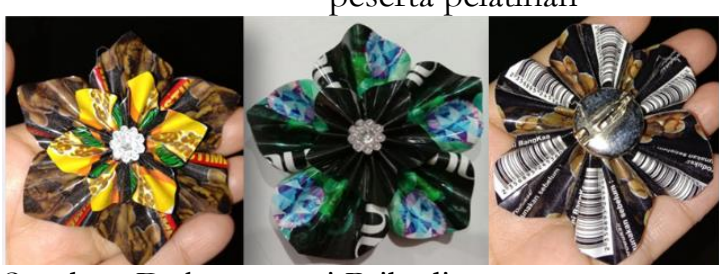

Sumber: Dokumentasi Pribadi

Gambar 5:

Tas dari sampah plastik hasil kreativitas peserta pelatihan

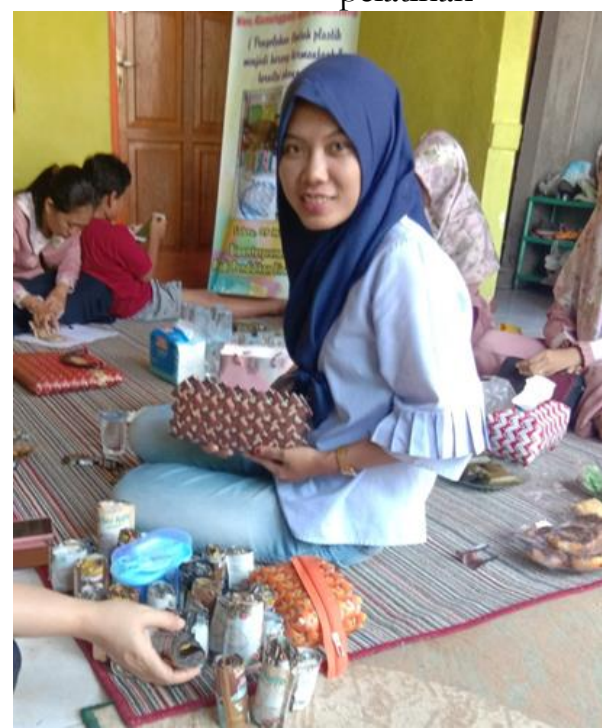

Sumber: Dokumentasi Pribadi

Melalui kegiatan ini, diharapkan masyarakat Kelurahan Kalisegoro Kecamatan Gunungpati Kota Semarang, khususnya ibu rumah tangganya dapat meningkatkan kepedulian dalam pengolahan sampah dan menjadikan sampah plastik yang biasanya terbuang menjadi lebih bermanfaat. Pengolahan sampah plastik tersebut juga diharapkan dapat mengurangi timbunan sampah yang dapat mencemari lingkungan.

\section{KESIMPULAN}

Permasalahan sampah plastik di Kelurahan Kalisegoro Kecamatan Gunungpati Kota Semarang dapat menjadi ladang kreativitas bagi ibu rumah tangga di wilayah tersebut. Bermodalkan sedikit usaha dalam memilah sampah dan kreativitas dalam membentuk 
pola tertentu, sampah plastik dapat diolah menjadi produk dengan nilai ekonomi tinggi, seperti bros dan tas. Masyarakat cukup menyiapkan sampah plastik yang telah dipilah dan peralatan rumah tangga untuk membuat kerajinan tangan tersebut. Keterampilan yang didapatkan peserta pelatihan dapat dijadikan sebagai modal awal untuk meningkatkan pendapatan rumah tangga masing-masing.

\section{DAFTAR PUSTAKA}

Kurniaty, D. R., \& Rizal, M. (2011). Pemanfaatan hasil pengelolaan sampah sebagai alternatif bahan bangunan konstruksi. SMARTek, 9(1).

Nugraha, W. D., Suri, D. A., \& Syafrudin, S. Studi Potensi Pemanfaatan Nilai Ekonomi Sampah Anorganik melalui Konsep Daur Ulang dalam Rangka Optimalisasi Pengelolaan Sampah (Studi Kasus: Kota Magelang). Teknik, 28(1), 9-20.

Nurjazuli, N. Teknologi Pengolahan Sampah Organik Menjadi Kompos Cair.

Sahil, J., Al Muhdar, M. H. I., Rohman, F., \& Syamsuri, I. (2016). Sistem pengelolaan dan upaya penanggulangan sampah di Kelurahan Dufa-Dufa Kota Ternate. BIOeduKASI, 4(2).

Subekti, S. (2010). Pengelolaan Sampah Rumah Tangga 3R Berbasis Masyarakat. Prosiding SNST Fakultas Teknik, 1(1).

Wahyono, S. (2001). Pengolahan sampah organik dan aspek sanitasi. Jurnal Teknologi Lingkungan, 2(2).

Yudhistirani, S. A., Syaufina, L., \& Mulatsih, S. (2016). Desain Sistem Pengelolaan Sampah Melalui Pemilahan Sampah Organik Dan Anorganik Berdasarkan Persepsi Ibu-Ibu Rumah Tangga. JURNAL KONVERSI, 4(2), 29-42. 